\title{
Enquadramentos, precariedade e resistências situadas do/as trabalhadore/as do sexo contra os processos de criminalização implantados pelo governo do tráfico na
} Argentina $^{1}$

\section{Frames, precariousness and resistance of sex workers against the criminalization processes implemented by the government of trafficking in Argentina}

Agustina Iglesias Skulj²

\section{Introdução}

$\mathrm{Na}$ abundante literatura dedicada ao estudo de políticas contra o tráfico sexual de mulheres cis ${ }^{3}$, encontramos várias tentativas de desenvolver ferramentas analíticas capazes de mitigar a natureza ambígua da definição legal do Protocolo de Palermo contra o tráfico (doravante o Protocolo) ${ }^{4}$, e sua tradução igualmente

\footnotetext{
${ }^{1}$ Tradução do espanhol para português realizada por Fernanda Martins e Fiammetta Bonfigli.

${ }^{2}$ Doutora em Direito pela Universidade de Salamanca, criminóloga transfeminista e pesquisadora independente.

Email: fermelita@gmail.com

3 N.T.: A expressão cis indica uma identidade de gênero assumida pela pessoa em conformidade àquela anunciada biologicamente no nascimento, já a expressão trans expressa uma identidade de gênero reivindicada em oposição à determinação biológica.

4 Este instrumento foi aprovado em 2000 e é complementar à Convenção das Nações Unidas contra o Crime Organizado Transnacional e visa prevenir, suprimir e punir o tráfico de pessoas, especialmente crianças e mulheres. Da mesma forma, nessa ocasião, o Protocolo Contra o Contrabando de Migrantes por Terra, Mar e Ar foi promulgado. No contexto da elaboração do Protocolo sobre Tráfico, discussões acaloradas ocorreram para chegar a uma definição de crime que conseguisse superar os marcos históricos que o identificaram, sem mais nuances, com a prática da prostituição. No entanto, os esforços para chegar a uma definição típica, consistente com o princípio da legalidade penal, colidiram frontalmente com as trajetórias normativas relativas a prostituição em cada um dos Estados participantes. Nesse sentido, a Argentina e os Estados Unidos da América do Norte têm posições que não são completamente assimiláveis, mas representam a posição abolicionista da prostituição. Suas posições ocuparam um lugar relevante nas discussões que
} 
deficiente para os sistemas penais legais locais. Nesse sentido, Kelly (2005) afirma que essa característica permite que esse crime seja potencialmente usado para criminalizar uma ampla gama de situações e comportamentos. Sua proposta, portanto, juntamente com a de muita/os outra/os autora/es, visa estabelecer uma distinção que desative a identificação entre prostituição voluntária e forçada.

Assim como foi moldado o delito na Argentina, retomando as diretrizes do Protocolo, não é possível distinguir entre uma situação de exploração sexual que configura a referida conduta e prostituição exercida voluntariamente (IGLESIAS SKULJ, 2013, 284 e segs.) 5 Como apontamos, essa identificação deu origem a uma profusa literatura crítica sobre os processos de criminalização implementados pelas políticas criminais que foram projetadas para combater a exploração sexual (BERNSTEIN, 2012; HOANG \& PARREÑAS, 2014; SANDERS, O'NEILL \& PITCHER, 2009; SAUNDERS \& SODERLUND, 2003; VARELA, 2013; WEITZER 2011; DAICH E VARELA AMMAR / REDTRASEX, 2015; 2016; ANISTIA, 2016). Nesta ocasião, nossa proposta consiste em incorporar essa ambiguidade à análise, uma vez que ela abre linhas mais produtivas de problematização (AGUSTÍN, 2007;

levaram à redação final deste instrumento. O artigo 3 estabelece que: a) "Tráfico de seres humanos" significa o recrutamento, transporte, transferência, acolhida ou recepção de pessoas, recorrendo à ameaça ou uso da força ou outras formas de coerção, sequestro, fraude, engano, abuso de poder ou situação de vulnerabilidade ou concessão ou recebimento de pagamentos ou benefícios para obter o consentimento de uma pessoa que tem autoridade sobre outra, para fins de exploração. Essa exploração incluirá, no mínimo, a exploração da prostituição de terceiros ou outras formas de exploração sexual, trabalho ou serviços forçados, escravidão ou práticas análogas à escravidão, servidão ou remoção de órgãos; b) O consentimento dado pela vítima de tráfico de pessoas a todas as formas de exploração intencional descritas na seção a) deste artigo não será levado em consideração quando algum dos meios estabelecidos na referida seção tiver sido utilizado; c) $\mathrm{O}$ recrutamento, transporte, transferência, recepção ou acolhimento de uma criança para fins de exploração será considerado "tráfico de seres humanos", mesmo quando nenhum dos meios estabelecidos na seção a) deste artigo for utilizado.

5 Em 2008, foi aprovada a Lei 26.364, que introduziu a criminalização do crime de tráfico de pessoas no artigo 145 bis, que estabeleceu uma "sentença de três a seis anos de prisão para quem captura, transporte ou transfere, dentro e fora do país, acolhe ou recebe pessoas com mais de 18 anos de idade ao praticar enganos, fraudes, violências, ameaças ou qualquer outro meio de intimidação ou coerção, abuso de autoridade ou de uma situação de vulnerabilidade, concessão ou recebimento de pagamentos ou benefícios para obter o consentimento de uma pessoa que tenha autoridade sobre uma vítima, para fins de exploração". No caso de menores, conforme disposto no art. 145 ter. a redação foi mantida independentemente do meio delitivo, pois esses sujeitos não podem dar consentimento sob nenhuma circunstância. Em 2012, após a promulgação da Lei 26.842, houve uma reforma substancial do crime de tráfico de pessoas e naquelas disposições que puniam os cafetões (artigos 125 bis e seguintes). A reforma eliminou diretamente a distinção entre adultos e menores, os meios comissivos foram eliminados e a sentença foi aumentada para uma sentença de 4 a 8 anos. A redação atual do art. 145 bis, fica da seguinte forma, a referida penalidade deve corresponder "à pessoa que oferece, captura, transfere, recebe ou acolha pessoas com a finalidade de exploração, seja no território nacional ou de ou para outros países, mesmo que o consentimento da vítima seja mediado". A situação de vulnerabilidade como meio comissário significa um agravamento da sentença do Artigo 145 ter, será de cinco (5) a dez (10) anos. 
MUNRO E SCOULAR, 2012), não necessariamente cercadas por uma interpretação dogmática e político-criminal cujo objetivo é a redução da ambiguidade da tipificação legal no campo judicial.

Assim, a ambiguidade predicada deve ser analisada como condição de possibilidade para a proliferação de leis, atos administrativos, agências especializadas e áreas de institucionalização do feminismo abolicionista ${ }^{6}$, cuja definição da "experiência" feminina7 (MACKINNON, 1982; 1995) tem sido muito relevante para a configuração do que foi chamado de "paradigma da violência de gênero". ${ }^{8}$

O último refere-se à "violência de gênero" como uma categoria político-legal que promoveu formas específicas de intervenção, interpretação e tratamento para abordar as múltiplas opressões às quais as mulheres estão expostas; essas formas também são usadas para ler as opressões de outras identidades de gênero, lésbicas, bissexuais, intersexuais, transexuais ou travestis, com efeitos altamente criticáveis (TREBISACCE, 2020, p. 120). Inserido nesse paradigma, o tráfico de mulheres para fins de exploração sexual ocupa um lugar preponderante na agenda de direitos humanos em nível global desde o final dos anos 90 (MILLER, 2004, p. 21). Sua

\footnotetext{
6 N.T.: A expressão feminismo abolicionista direciona ao movimento interno de algumas perspectivas feministas que buscam a abolição da prostituição, entendendo-a como uma expressão da submissão às hierarquias de opressão relacionadas às mulheres, conforme se buscará demonstrar ao longo do artigo.

7 No feminismo abolicionista - da prostituição -, seu grande expoente, Catherine MacKinnon apontou que há uma experiência comum de dominação que torna todas as mulheres sexualmente subordinadas. A partir desse raciocínio, o feminismo radical defende a dissolução da estrutura individualista, naturalista, idealista e moralista do direito androcêntrico. Para a autora (1995: 391), a situação das mulheres no campo jurídico é definida através da opressão sexista, instrumentalizada para descrever a verdadeira experiência de todas as mulheres, e é fruto de uma premissa que define a sexualidade feminina como objeto de dominação pelos homens. Diante da alienação e da falsa consciência que esse tipo de dominação produz, MacKinnon (1982, p. 637; 1995, p.187) propõe como método, a tomada de consciência a fim de revelar a verdade oculta pela dominação masculina; Essa busca por uma verdade transcendente e universal lhe permite confiar no surgimento de uma "nova mulher" que, através da consciência coletiva, pode transcender as determinações do sistema de dominação. Nesta proposta epistemológica, tanto a vitimização quanto a dominação são analisadas como o produto de um patriarcado a-histórico, liso e homogeneamente opressivo. No nível internacional, essa influência explica a notoriedade de que a violência sexual adquirida como forma de tortura de gênero facilitou a visibilidade do fenômeno como típico do campo dos direitos humanos, dada sua capacidade de descrever uma situação cuja crueldade ninguém poderia ignorar. No âmbito da lei, essa violência específica e original permitiu invocar uma opressão comum a todas as mulheres do mundo. Juntamente com a responsabilidade dos Estados, essa alegação também pretendia deslocar as considerações sobre a honestidade das mulheres, a partir da incorporação de elementos normativos de gênero que poderiam se refletir no direito internacional positivo.

${ }^{8}$ Nas Nações Unidas (ONU), durante a Década das Mulheres (1975-1985), a violência ocupava um lugar cada vez mais relevante nas estratégias para exigir a proteção internacional dos direitos humanos. Na Conferência de Viena de 1993, a violência contra as mulheres foi fortalecida como uma categoria de análise e demanda - simultaneamente - para combater as violações dos direitos humanos contra as mulheres, que até então eram analisadas como uma questão de discriminação.
} 
consolidação na arena internacional descreve um processo no qual a participação do feminismo na governança (HALLEY et al., 2006, p. 340) 9 foi crucial na problematização do tráfico de pessoas, não apenas no nível internacional, mas por causa da capacidade de influência que teve nos contextos locais (Piscitelli, 2015). Dessa maneira, essa contribuição é inserida nos desenvolvimentos teóricos que analisam os regimes anti-tráfico (PISCITELLI, 2015) ${ }^{10}$ como parte da governamentalidade neoliberal, retomando também para a análise as críticas à categoria de gênero em que se baseiam nas descrições de experiências de exploração sexual11 (ABRAMS, 1995, 310) e as análises relacionadas à tradução das demandas feministas pela proteção dos direitos humanos em uma chave punitiva. Especificamente, no âmbito do Protocolo, o feminismo (neo)abolicionista ${ }^{12}$ definiu a exploração sexual como o surgimento de uma nova/moderna escravidão, como a manifestação mais violenta do patriarcado, e apontou a falsa consciência daqueles que consentem com a prostituição, insistindo no dano irreparável que isso gera.

\footnotetext{
9 Halley cunhou o termo governança feminista para se referir aos processos através dos quais as reivindicações feministas conseguiram se estabelecer em instituições nacionais e internacionais. $\mathrm{O}$ artigo é apresentado como um diálogo entre várias autoras que analisam diferentes campos de intervenção, nos quais o tráfico sexual ocupa um lugar muito relevante. Esse feminismo emprega uma estratégia fragmentada e dispersa no campo do direito, influenciando não apenas as formas de legislar, litigar ou elaborar políticas públicas, mas também campanhas para conscientizar sobre as questões que afetam as mulheres. Halley ressalta que essas estratégias andam de mãos dadas com o feminismo jurídico norteamericano, que desde a década de 1990 teorizou repetidamente sobre o direito penal e as formas de controle social, inserindo-se sem maiores dificuldades na "virada punitiva" denunciada pela literatura criminológica norteamericana e latino-americana desde os anos oitenta.

${ }^{10}$ Aqui retomamos a expressão cunhada pela autora de "regimes antitráfico", que alude à constelação de políticas, normas, discursos, conhecimentos e leis sobre tráfico de pessoas, formuladas no entrelaçamento de níveis supranacionais, internacionais, nacionais e locais ${ }^{11}$ As definições de feminismo radical para combater a prostituição, a pornografia e o assédio sexual começaram a operar em um nível juridico, mas também como a imagem que as mulheres construíam de si mesmas. Esse feminismo concebe a sexualidade da mulher como o espaço paradigmático de opressão e como constitutivo da definição de gênero a partir da qual parte, como expressa por TiGrace Atkinson, quando afirma que não existe feminista digna de tal pertença que, forçada a escolher entre liberdade e sexo, incline-se para o último.

${ }^{12}$ Neste texto, a expressão (neo)abolicionismo refere-se não apenas a uma questão temporal como vetor de diferenciação com as campanhas anteriores contra o tráfico de mulheres brancas, mas a uma forma particular de governo de prostituição que utiliza elementos da criminologia positivista como método de tornar invisíveis as condições estruturais dos mercados de trabalho cada vez mais informais e precários. O prefixo (neo) pretende marcar uma distinção, e também continuidades, com o movimento de prostituição abolicionista no contexto da luta contra o comércio de brancas à cavalo entre o final do século XIX e o início do século XX na Inglaterra e França. Embora o objetivo de acabar com a prostituição permaneça, desde que o Protocolo foi promulgado, o que se busca é desencorajar a demanda por serviços sexuais como um método eficaz para atingir esse objetivo. $\mathrm{O}$ Modelo Sueco, que busca a criminalização do cliente de serviços sexuais, estabelece uma diferenciação das diferentes formas de exploração no contexto do tráfico de pessoas, priorizando o objetivo da exploração sexual, equiparada ao exercício da prostituição, abstraindo-a de influências sociais ou das políticas de redução de danos e optando pela criminalização da demanda.
} 
Atribuídas essas características à exploração sexual, o perfil da vítima de tráfico sexual é uma mulher que foi privada de sua dignidade e liberdade, através do processo de submissão à prostituição, mesmo com seu consentimento.

Como já apontamos, as críticas ao contexto neoliberal em que as políticas de tráfico sexual são desenvolvidas são muito sugestivas, em primeiro lugar, aquelas que apontam que essa forma de governo se baseia na responsabilidade de um sujeito que toma decisões racionais e, em segundo lugar, questões relativas às medidas adotadas sob essa racionalidade (BERNSTEIN 2012; HOANG E PARREÑAS 2014; SANDERS, ET.AL, 2009; SAUNDERS E SODERLUND, 2003; WEITZER 2011). São interessantes também outras investigações que problematizam a situação de pânico sexual em que são desenvolvidas as políticas de combate ao tráfico e as maneiras pelas quais a luta contra esse crime é usada para redesenhar as respostas a situações tão variadas como pobreza, migrações, direitos trabalhistas, segurança e violência de gênero em chave punitiva (BERNSTEIN, 2012; CHAPKIS 2003; WEITZER, 2011).

Especificamente, Claudia Aradau (2004, p. 254) destaca que o Protocolo é um instrumento paradigmático das relações entre os discursos de segurança e proteção dos direitos humanos, e que a suposta incompatibilidade entre eles é desarmada por meio de intervenções promovidas sobre a conduta de coletivos e vítimas individualizadas. Segundo Aradau, o discurso humanitário funciona a partir do que ela definiu como "política de compaixão", onde as intervenções são modeladas através das emoções despertadas pela vítima e, estas por sua vez, articuladas com "políticas de risco" que intervêm por meio de tecnologias de gerenciamento atuariais.

Não surpreende, portanto, que o tráfico sexual seja problematizado como uma questão simplificada de punição de traficantes e resgate de vítimas, ambas com perfis racializados (KOTISWARAN, 2014). Esse olhar dicotômico foi chamado de "abordagem trafiquista” (AGUSTIN, 2007) e é o resultado da linguagem excepcional e homogênea que gera novas hierarquias e formas de inclusão/exclusão de sujeitos ameaçados (ARADAU, 2008) nessa área. De fato, as definições (neo)abolicionistas de prostituição foram facilmente instrumentalizadas por um modelo jurídico que parte de uma concepção essencialista de violência, cujo resultado mais imediato é visto na criminalização do trabalho sexual em suas 


\section{6 | Opinião Filosófica, n. Ed. Esp. 2 (2020) - Biopolítica(s) no século XXI}

múltiplas expressões, fundamentalmente quando consegue articular alguma forma de organização estável.

Portanto, o governo do tráfico sexual, como parte do paradigma da violência de gênero, promove que um maior número de conflitos relacionados à segurança das mulheres se traduza em intervenções excepcionais, aumento de penas e/ou sobre a eficácia das forças de segurança no combate a essa emergência (BUMILLER, 2008, P. 114; SCOULAR, 2004, P. 345). Além disso, esse paradigma incorporou acriticamente o conhecimento especializado sobre o controle de populações e indivíduos perigosos, típico do controle da prostituição desde o final do século XIX; no entanto, esses controles são modulados atualmente por meio da categoria do risco.

Retomando as críticas do feminismo pós-colonial, Elizabeth Bernstein (2010; 2012) apontou a natureza complexa das alianças entre feministas (neo)abolicionistas, autoridades religiosas e ONGs mobilizadas para empoderar as mulheres subalternizadas do sul-global no contexto da governança feminista do tráfico (HALLEY et al., 2006; KAPUR, 2005; KEMPADOO E DOEZEMA, 1998). A autora ressalta que essa forma particular de governo se configura como uma das expressões mais relevantes do que ela chamou de "carceral feminism" e que traduzimos livremente como feminismo punitivista.

Por sua parte, Laura Agustín (2007) cunhou o termo "indústria do resgate" para denunciar a capacidade expansiva da definição de tráfico sexual, cuja sustentabilidade dependerá da existência de um número crescente de mulheres que se assumam como vítimas, mesmo através da ameaça de punição. Isso também explica as razões pelas quais o tráfico sexual se tornou uma commodity na competição por recursos econômicos de Estados e ONGs, bem como reconhecimento político e acadêmico, como demonstrado pelo sistema de prêmios e punições estabelecido pelas agências norteamericanas nos relatórios anuais do Trafficking in Persons Report, que condiciona o financiamento de programas para combater esse crime ao cumprimento do juramento de abstenção para promover a indústria do sexo que deve ser assumido por quem aspira a se beneficiar desses fundos ${ }^{13}$ (VARELA, 2015).

\footnotetext{
${ }^{13}$ A partir desta cláusula, muitas organizações deixaram de receber financiamento. As queixas mais contundentes vieram de organizações que trabalhavam nas políticas de redução de danos do HIV/AIDS com trabalhadore/as do sexo, uma vez que essas atividades, distribuição de preservativos, 
De mãos dadas com essas definições, faremos uma análise das políticas de combate ao tráfico sexual, estabelecendo como ponto de partida que elas não consistem em novas intervenções com o objetivo de defender ativos ou pessoas já existentes, mas criar novas esferas de governamentalidade (VALVERDE, 2010, p. 4). Essa afirmação impede que a definição de exploração sexual seja analisada como algo estático no âmbito da lei e, pelo contrário, sua natureza dúctil é inestimável para o enquadramento ${ }^{14}$ (BUTLER, 2006, p. 16; 2010, p. 24) dessas práticas.

\section{Para o resgate das vítimas: empoderamento punitivo}

Nesta seção, propomos incorporar a ambiguidade à análise como uma ferramenta a partir da qual podemos estabelecer, primeiro, as relações entre os elementos heterogêneos que compõem os regimes antitráfico e, segundo, a maneira como são implantadas tais relações para dar legitimidade às intervenções em chave punitiva. Especificadamente, será analisada a categoria de situação de vulnerabilidade $^{15}$ (VARELA, 2013), que formalmente atua como suposto fator agravante da pena do delito decorrente da reforma da lei 26.842 em 2012; e materialmente, na esfera judicial, funciona como um ponto de partida para criminalizar o trabalho sexual e suas resistências. No entanto, como já apontamos, a análise dessa categoria proposta neste texto visa tornar visíveis as justificativas que permitem que o patriarcado, a vulnerabilidade e a exploração sejam instrumentalizadas para aumentar a intensidade e a extensão das tecnologias do

oficinas sobre acesso à saúde abrangente, etc.começaram a ser interpretadas como promotoras do trabalho sexual.

$14 \mathrm{~A}$ ação de enquadramento refere-se especificamente aos desenvolvimentos relacionados à precariedade realizados por Judith Butler. Nesse sentido, para essa autora, os quadros são esquemas de inteligibilidade móvel e, portanto, permitem que a existência de versões minoritárias da norma seja incorporada à análise, ou seja, o enquadramento permite questioná-lo através da visibilidade das resistências frente às tentativas violentas normalizadoras. Desenvolveremos esses conceitos no último ponto.

${ }^{15} \mathrm{~A}$ importância de ancorar a análise nesta categoria reside no fato de que ela encerrou os debates entre o feminismo abolicionista e o feminismo em favor do trabalho sexual no contexto das discussões que concluíram a elaboração do Protocolo. Dessa maneira, a descrição típica contém os meios comissivos como pressuposto da inexistência de consentimento e como premissa para determinar a nocividade do bem jurídico protegido. No entanto, a situação de vulnerabilidade permaneceu indefinida e, portanto, foi deixada nas mãos da/os operadora/es judiciais e outra/os atora/es envolvida/os no desenvolvimento de políticas antitráfico, o escopo desta categoria. $\mathrm{Na}$ Argentina, a situação de vulnerabilidade deixou de funcionar como suposição de agravamento da sentença - meio comissivo - e foi interpretada como a situação que descreve a prática da prostituição sem nuances adicionais. 


\section{8 | Opinião Filosófica, n. Ed. Esp. 2 (2020) - Biopolítica(s) no século XXI}

controle sobre mulheres cis, mulheres trans e travestis que estão envolvidas no trabalho sexual.

De fato, desde a incorporação do crime de tráfico sexual no sistema jurídicopenal argentino, o resgate de vítimas trabalha contra alguém que não pode ser responsabilizado pelo fato de exploração sexual, mas quem é obrigado a desenvolver ferramentas para reduzir a situação de vulnerabilidade em que se encontra (KOTISWARAN, 2014, p. 365). Nas condenações judiciais por esse crime, o conhecimento especializado dos que intervêm no processo judicial de tráfico sexual descreve, com mais ou menos detalhes, a vulnerabilidade de mulheres no "sistema de prostíbulo"16 (COLOMBO E MANGANO, 2011). Ao contrário do tráfico para fins de exploração laboral, os mecanismos não foram projetados para determinar quando estamos diante de um ato punível de exploração, uma vez que a concepção de gênero da qual eles partem lhes evita esse esforço (IGLESIAS SKULJ, 2017, p. 18).

A investigação judicial do tráfico sexual se esgota na existência da prostituição como sinônimo de situação de vulnerabilidade. O exposto acima mostra que, apesar de a letra da lei criminal não punir diretamente aqueles que realizam essa atividade, ou seja, permanece atípico o comportamento de pagar um preço pela prestação de um serviço sexual, criminaliza qualquer pessoa que intervém no desenvolvimento do mesmo, mesmo com o consentimento da vítima. A vulnerabilidade abrange um conjunto de características - suscetíveis de serem sempre expandidas - associadas à prática da prostituição como área de vitimização per se. Essas interpretações jurisprudenciais - ancoradas na premissa abolicionista de que a prostituição é sempre exploração sexual - permitem perseguir e punir as múltiplas formas de resistência à criminalização dos modos de vida da/os trabalhadore/as do sexo (por exemplo, a criminalização de troca de informações por meio de redes sociais e até formas muito rudimentares de organização da atividade, a afiliação ao Sindicato da/os Trabalhadore/as do Sexo [AMMAR] funciona como um pressuposto para a configuração da exploração sexual, e o aumento da violência institucional é legitimado em espaços públicos, especialmente contra mulheres migrantes e travestis, entre outros efeitos). Nesse contexto, a/os trabalhadore/as do

\footnotetext{
${ }^{16}$ De acordo com o procurador geral da Protex Dr. Marcelo Colombo, 99\% dos casos do sistema de prostituição são tráfico sexual”, disponível em http://www.diariofemenino.com.ar/marcelocolombo-el-99-de -os-casos-do-sistema-de-prostituição-sobre-tráfico-de-sexo.
} 
sexo são forçada/os a decidir entre sua liberdade ou segurança e, nessa chave, articulam estratégias contra a exposição diferencial à violência institucional.

Para elaborar essa análise, é interessante analisar as ações do Programa Nacional de Resgate e Acompanhamento de pessoas afetadas pelo crime de tráfico (doravante PNRAPDT) ${ }^{17}$ do Ministério da Justiça e Direitos Humanos e sua campanha "sem clientes não há tráfico", que publica até dezembro 2015 um total de 10.000 mulheres "resgatadas" e quase 6000 ligações recebidas na linha de denúncia anônima \#145 (desde abril de 2008). O objetivo do PNRAPDT é fornecer assistência psicológica às ações das forças de segurança federais durante as buscas e "preparar" as vítimas para sua "declaração" em tribunal. Zaida Gatti, chefa do programa, afirmou que "... do total, entre 60\% e 70\% são vítimas de exploração sexual, ou seja, são mais 7000 mulheres que auxiliamos por esse crime, das quais apenas as $2 \%$ se reconhece como vítima. Em proporção, nove em cada 10 procedimentos correspondem à exploração sexual"18 (o destaque é nosso).

Como se demonstra acima, a vulnerabilidade no crime de tráfico sexual resulta de suposições morais e corporais estáticas e essenciais em que se sustentam os privilégios e a definição de exploração sexual do feminismo (neo)abolicionista; isto é, as "soluções" baseiam-se em uma definição de gênero que opera como uma categoria totalizante, incapaz de compreender os processos de racialização, precariedade ou o acoplamento de diferentes sistemas de opressão que descrevem a situação de sujeitos particulares. Essa perspectiva define a vulnerabilidade como uma relação entre o corpo e a subjetividade, que opera como uma negação das experiências do/as trabalhadora/es do sexo que abrem instâncias punitivas não contempladas na lei.

Para explorar essa afirmação, recuperaremos as análises de precariedade ${ }^{19}$ de Judith Butler (2010, p.15) como um método para delimitar as implicações

\footnotetext{
${ }^{17}$ A resolução MJSyDH 2198/2008 criou o Gabinete de Resgate e Acompanhamento para pessoas afetadas pelo crime de tráfico e foi modificada em 2012 através da Resolução MJyDH 731/2012, que pôs em operação o Programa Nacional de Resgate e Acompanhamento de pessoas afetadas pelo crime de tráfico.

${ }^{18}$ De acordo com o procurador geral da Protex Dr. Marcelo Colombo, 99\% dos casos do sistema de prostituição são tráfico sexual", disponível em http://www.diariofemenino.com.ar/marcelocolombo-el-99-de -os-casos-do-sistema-de-prostituição-sobre-tráfico-de-sexo /

${ }_{19}$ Em Quadros de Guerra, Butler usa o termo vulnerabilidade em diversas ocasiões, e aparece quase sempre em relação à precariousness, ou seja, ao aspecto corporal da precarity (em espanhol para diferenciar os dois conceitos se usa o termo precaridad para o primeiro dos conceitos e precariedad para o citado por ultimo). Agora, o que queremos ressaltar é que, diferentemente da vulnerabilidade, a precariedade explica a natureza social da vida, ou seja, não se trata da exposição de nosso corpo a perdas ou violência, mas o fato de que nossa a vida depende de outras pessoas próximas ou não. De
} 
individualizadoras da situação de vulnerabilidade. As contribuições butlerianas são uma grande contribuição para as discussões atuais sobre os enclaves analíticos de biopolítica e governamentalidade de Foucault. Embora Foucault (2004) não tenha sido muito preciso na definição de biopoder (HARCOURT, 2008; VALVERDE, 2008) ${ }^{20}$, Rabinow e Rose (2006, p.197) sugerem que o termo biopolítica pode ser usado para analisar estratégias específicas de governo e suas resistências. Em outras palavras, esse conceito é útil na medida em que possibilita um espaço para fazer problematizações sobre as formas de poder/saber que se desdobram sobre a vida, seus regimes de verdade e as práticas de intervenção no campo do tráfico sexual. Por outro lado, o termo governamentalidade nos permite analisar a passagem do modelo disciplinar da prostituição para as tecnologias fornecidas pelo governo do tráfico para empoderar as mulheres vítimas de exploração sexual (cf. ROSE, et. al., 2006). Nesse sentido, Valverde (2008, p. 213) destaca que é plausível usar a governamentalidade para analisar os postulados neoliberais da eficiência da intervenção em diferentes projetos biopolíticos; isto é, a governamentalidade permite que os elementos autoritários sejam visíveis mesmo em regimes que partem da consideração da vida sob o postulado liberal de um sujeito soberano.

No entanto, Laurent Berlant (2007, p. 758) sustenta que a concepção de soberania como autonomia individual produz que o controle que o próprio sujeito exerce sobre si mesmo seja equiparável às funções de controle estatal sobre fronteiras geográficas. Essa perspectiva de soberania permite certas leituras melodramáticas de agência/consentimento e fornece um álibi para o governo, enquanto confere certa legitimidade a intervenções de natureza moralizante contra o comportamento indesejado dos indivíduos. Essas descrições sobre a agência do sujeito e os atos dela decorrentes permitem que qualquer comportamento que não

qualquer forma, deve-se notar que nenhum desses conceitos existe fora do político, do social. O "ser" do corpo ao qual essa ontologia se refere é um ser sempre comprometido com os outros: com as normas, com as organizações sociais e políticas que foram desenvolvidas historicamente para maximizar a precariedade para alguns e minimizá-lo para outros. Essa relação com os outros permite o surgimento do sujeito, sempre dependente (precário) e exposto a outros (vulnerável). Precaridad e precariedad são conceitos que mantêm uma relação de interseção: "Vidas são por definição precárias: podem ser eliminadas voluntária ou acidentalmente, e sua persistência não é garantida de forma alguma. Em certo sentido, é uma característica de toda a vida e não existe uma concepção de vida que não seja precária, [...] A precariedade designa essa condição politicamente induzida na qual certas populações sofrem com a falta de redes de apoio social e econômico e eles estão diferencialmente mais expostos a danos, violência e morte [...] ". (BUTLER, 2010, p. 46).

${ }^{20}$ De fato, nos cursos que fazem parte de Segurança, Território, População, o termo biopolítica aparece nas primeiras lições, mas Foucault ao longo do curso afirma que "governamentalidade é um termo mais apropriado para designar o mesmo" (FOUCAULT, 2004, p. 67). 
segue esses padrões seja analisado como falta de responsabilidade, como recusa de tratamento ou diretamente, incapacidade de empoderarse. Se analisarmos as declarações feitas pela chefa do PNRAPDT transcritas acima, as intervenções para proteger as mulheres no contexto do tráfico sexual partem de uma definição de empoderamento que funciona/opera como consentimento o de uma mulher cis capaz de tomar boas decisões, de se autogovernar (HACKETT, 2013; HANNAHMOFFAT, 2000; 2006). Nesse caso, são bem-sucedidas as decisões que apontam para o reconhecimento da situação de vulnerabilidade no mercado sexual como algo intrínseco a ele e, portanto, o abandono dessa atividade é a única possibilidade de reduzir a exposição à vulnerabilidade.

De fato, a operacionalização da situação de vulnerabilidade no contexto das políticas antitráfico permite que as tecnologias disciplinares da prostituição se entrelaçam com as novas tecnologias de resgate, reforçando-se mutuamente (BROWN, 2014, 2015). Por exemplo, a situação de vulnerabilidade é fundamental ao traçar o perfil usado pelo/as diferentes operadore/as (equipes de resgate, forças de segurança e judiciário, feminismo (neo)abolicionista, ONGs) e inclui duas situações possíveis: a vítima representa um risco para si mesma, por não ser capaz de se autoproteger de situações de exploração devido à sua vulnerabilidade e, simultaneamente, isso representa um risco para o sucesso das políticas de combate ao tráfico. Especificamente, a situação de vulnerabilidade molda o perfil da vítima: estamos diante de uma mulher cis atravessada por duas categorias aparentemente contraditórias que não podem ser diferenciadas entre si: 1) se se assumem como trabalhadoras sexuais, devem ser reprimidas como "traficantes" ou cafetinas, embora o código penal não tipifique a prática da prostituição; 2) Como vítimas (99\% delas de acordo com os números estratégicos), elas devem ser resgatadas e ajudar a permitir que se tornem sujeitos autônomos, ou seja, abandonem o trabalho sexual. Nessa mesma linha, o Protocolo de ação das forças de segurança ${ }^{21}$ para a investigação desse crime define o empoderamento como a instância em que a vítima desenvolve outras estratégias de sobrevivência que não são trabalho sexual, que

\footnotetext{
${ }^{21}$ Resolução do Ministério de Segurança $\mathrm{n}^{0}$ 742/2011 "Protocolo de Actuación para las fuerzas federales" disponível em http://www.infoleg.gov.ar/infole-gInternet/anexos/185000189999/185854/norma.htm
} 
testemunhem em processos judiciais contra "o traficante" e que, no caso das pessoas migrantes, que retornem ao seu local de origem.

Como mostra a pesquisa de Cecilia Varela (2013), um dos efeitos mais relevantes da implementação de políticas de combate ao tráfico é o aumento da criminalização das mulheres no mercado sexual, com índices ainda mais importantes do que no crime de tráfico de drogas, que até a implantação de políticas antitráfico, foi estabelecida como a primeira causa do encarceramento de corpos feminizados (TARANTINO, 2017). Do número total de condenações pelo crime de tráfico sexual, $43 \%$ correspondem a mulheres cis, apresentando números sem precedentes de criminalização, porque, ainda mais diante dos casos de tráfico sexual, as condenações apelam para as definições abolicionistas do mercado sexual e, portanto, reproduzem a identificação entre prostituição e exploração sexual.

Confrontado com esses resultados indesejados(?) surge a necessidade de denunciar as razões que permitem a expansão dos regimes antitráfico, apesar de seus fracassos. Nesse sentido, a situação de vulnerabilidade legitima o uso de técnicas de empoderamento que não são estritamente regulatórias, mas coercitivas (BERNSTEIN 2010; SAUNDERS \& SODERLUND 2003). Portanto, a descrição das formas de operação dessa categoria expõe as aparentes contradições de governo (neo)abolicionista do tráfico sexual e permite explicar os efeitos que as políticas de resgate geram quando se orientam para uma vítima de tráfico, que age sem agência e cujo empoderamento ocorre através de mecanismos que não se materializam fora do recurso à violência estatal (HANNAH-MOFFAT, 2004; 2010).

Agora, como sugere Lorey (2016, p. 47), o questionamento de técnicas governamentais baseadas na governamentalidade não deve se referir especificamente à regulamentação de sujeitos autônomos e livres, mas às relações pelas quais os sujeitos chamados autônomos e livres se tornam tais em primeira instância. Nesse sentido, as políticas antitráfico destacam a natureza ambivalente entre hetero e autogoverno. Seguindo esse raciocínio, devemos analisar o resgate como uma tecnologia (pós)disciplinar de governo da prostituição e que, quando articulada à situação de vulnerabilidade, produz criminalização das resistências que opõem as trabalhadoras sexuais diante dessas tentativas, perpetuando assim o governo do tráfico sexual. Ou seja, na última década houve uma capilarização meticulosa do processo de criminalização da prostituição, baseada na promulgação de leis, regulamentos, atos administrativos, na criação de novas estruturas 
ministeriais de várias fileiras, alianças com outros autores políticos, da influência do feminismo (neo)abolicionista no nível institucional e no movimento feminista, entre outros fatores que favoreceram sua reprodução (Piscitelli, 2015). Grande parte da proliferação da institucionalização do governo do tráfico dependia, por um lado, de criminalizar a resistência da/os trabalhadora/es do sexo, alguns sindicalizados na AMMAR e, por outro, dos processos de estigmatização de seus modos de vida.

De fato, de acordo com esse raciocínio, a situação de vulnerabilidade funciona como uma modulação das fantasias do sujeito soberano (Lorey, 2016, p. 115) que tem em suas mãos a decisão de sair dessa situação, e essas fantasias são os eixos legitimadores das políticas de resgate. Como tentamos demonstrar, as políticas de combate ao tráfico obrigam a (auto) proteção das mulheres contra a ameaça de exploração sexual de um amplo espectro de "terceiros" e, dessa forma, aumenta e diversifica a vigilância sobre as formas de vida da/os trabalhadora/es do sexo, fundamentalmente cis mulheres. Nesse contexto, as complexas imbricações entre a tendência a abandonar o modelo disciplinar e as formas atuais de controle da prostituição podem ser explicadas - a partir da reflexão de Bernard Harcourt (1999, p. 112) - quando ele ressalta que as formas atuais de governo vão abandonando o "dano" como apoio a acusações criminais e pode se observar o surgimento da "vulnerabilidade" como uma maneira de legitimar a intervenção punitiva com um forte caráter moralizante.

Agora, o que acontece quando encontramos mulheres que resistem a ser "empoderadas" sob essas tecnologias? Em outras palavras, como devem ser analisadas as afirmações acima, que afirmam que no mercado do sexo $99 \%$ são vítimas de tráfico, contrastando com a evidência de que apenas $2 \%$ do total de pessoas resgatadas se assumem como tal? Com base nessa questão, buscamos enfatizar a natureza instável entre as esferas de governamentalidade e as relações de poder que proliferam nessa área, sob a organização dicotômica de discursos neoliberais e jurídicos; isto é, apesar das evidências do fracasso do resgate, sua continuidade é garantida graças ao silenciamento das vozes das trabalhadoras do sexo produzidas pela situação de vulnerabilidade, uma vez que esta determinará quando uma decisão é válida; isto é, a situação de vulnerabilidade protege o espaço das intervenções que falam em nome das mulheres para garantir a eficácia do resgate. O abandono do trabalho sexual (saída) em resposta à situação de 
vulnerabilidade é a rainha das intervenções, uma vez que, sob esse esquema, é possível atribuir qualquer falha nas políticas antitráfico à incapacidade de se empoderar das cis mulheres (SCOULAR \& O'NEILL, 2007), o que significa que, se você não se reconhecer como vítima, será punida como cafetina/traficante.

\section{Quadros, precariedade e exposição diferencial à violência do/as trabalhadore/as sexuais}

Diante do esquema proposto pelo governo (neo)abolicionista do tráfico sexual e, especificamente, da operatividade da situação de vulnerabilidade analisada no ponto anterior, nesta seção nos perguntamos quais outras problematizações podemos promover? Em princípio, essas profissionais deveriam ser capazes de contemplar as relações de poder e resistência situadas que encarnam as mulheres cis e trans e travestis, em troca da criminalização e estigmatização de seus modos de vida, que muitas vezes são formas de resistir às políticas de resgate.

Nesse contexto, a relevância da pergunta de Spivak (1988) sobre a (im)possibilidade da subalternizada falar nos permitiu, antes de tudo, analisar as tecnologias governamentais de tráfico que têm por objetivo empoderar as mulheres contra exploração sexual. Em segundo lugar, definir a situação de vulnerabilidade como uma condição de possibilidade para que o empoderamento se converta em coercitivo/moralizante, e também como uma fonte de legitimidade ao feminismo (neo)abolicionista, apresentado como a síntese superadora de outros modelos de governo de prostituição (IGLESIAS SKULJ, 2017).

No entanto, a situação de vulnerabilidade não deve ser considerada estritamente como uma tecnologia do poder soberano, mas como um regime de inteligibilidade que não apenas delimita o que é, mas o que pode ou não se tornar; isto é, o que eu posso "ser" é restringido antecipadamente por um regime de verdade que estabelece quais serão as maneiras de ser reconhecíveis, uma vez que esse regime oferece um quadro para o reconhecimento do sujeito através das normas estabelecidas para esse fim (BUTLER, 2009A, p. 37). Apesar de Butler estabelecer uma certa distância de Foucault, seguindo Victoria Dahbar (2018, p. 47), quando afirma que "[a]qui aparece a relação, nodal na teoria butleriana, entre alguns quadros - nesse caso, quadros do reconhecível como um tipo de quadro do inteligível - e algumas regras que delimitarão a figura desse sujeito, restrito pelos regimes de verdade. Essa categoria, cuja genealogia conceitual tem em Michel 
Foucault todo o seu referente, não é de total relevância para pensar o fenômeno abordado aqui; em certo sentido, são duas análises diferentes, uma vez que o interesse de Judith Butler não é tanto o que é considerado verdadeiro, mas o que é inteligível como real, aquilo que se é”.

Assim, a situação de vulnerabilidade como quadro é sempre uma determinação, uma qualificação do que é percebido como real, de acordo com um conjunto de regras mais ou menos explícitas que delimitam o possível. Butler ressalta que a noção de humano reconhecível é formada e reiterada repetidamente contra o que não pode ser nomeado ou considerado humano, uma figura do não humano que determina negativamente e potencialmente interrompe o reconhecível como tal (BUTLER, 2010, p. 96). De fato, as reflexões que realizamos neste texto não partem de uma concepção exclusiva prevista em lei, mas das várias configurações que incorporam o processo de sua reprodução.

Tornar-se inteligível - sempre de certa forma, não totalmente - "também depende da capacidade, invariavelmente coletiva, de articular uma alternativa, uma versão minoritária de normas ou ideais que sustentam e permitem que o indivíduo aja” (BUTLER, 2006, p. 16) O quadro, em suma, é uma consideração temporal mais que espacial, uma matriz que modula a relação entre o que é audível e o que não é, bem como as mudanças que ocorrem nessa relação (DAHBAR, 2018).

Portanto, a ideia de quadro possibilita substituir considerações binárias em relação à capacidade de "agência" e ao impacto que a situação de vulnerabilidade produz em seu reconhecimento; em outras palavras, devemos nos afastar dos postulados que incluem inclusão e exclusão em dois níveis separados e, em vez disso, analisar a situação de vulnerabilidade de uma perspectiva temporal que permita a implantação de uma tecnologia de inclusão diferenciada (PUAR, 2011). A temporalidade permite gradações relativas à capacidade/incapacidade de se empoderar, uma vez que o binômio deixou de funcionar como um jogo de soma zero, e a situação de vulnerabilidade deve ser entendida como uma modulação temporal do espaço turvado aberto entre essas duas instâncias.

Em suma, a ideia de temporalidade fornecida pelo quadro rompe com as interpretações relacionadas à biopolítica como uma tecnologia unidirecional cuja relação entre política e vida é sujeito/objeto (BENENTE, 2017, p. 22), e nos permite entender governamentalidade como um espaço onde táticas e fins se tornam difusos (BULTER, 2009, p. 85). Com efeito, a ênfase deve ser colocada nas matrizes de 
inteligibilidade para poder pensar sobre a produção diferencial da vida e sua relação com a política, enfatizando o caráter temporal produzido pela interseção entre inclusão e exclusão. Essa área de interseção implica não apenas pensar nos prazos da violência normativa que possibilitam versões do humano, com morfologias e modalidades, mas também em uma ontologia sócio-corporal, ou seja, as relações sociais que instituem "o humano" (DAHBAR, 2018, p. 14).

Já analisamos as maneiras pelas quais a categoria de situação de vulnerabilidade funciona, e afirmamos que ela não pode ser analisada em termos negativos, ou seja, como uma relação unidirecional e individualizante do sujeito soberano. Assim, devemos levar em consideração a natureza produtiva dessa categoria em termos da capacidade de articular os recursos disponíveis para mitigar a exposição à violência, mesmo em situações de vulnerabilidade.

Consequentemente, se dotarmos a vulnerabilidade do caráter interdependente que Butler atribui ao interseccioná-la com a precariedade, devemos analisá-la como uma instância temporal que distribui diferencialmente a exposição à violência normalizada do reconhecimento sobre o "humano" (DAHBAR, 2018). Isso nos permite considerar a precariedade como uma categoria que inclui na análise a natureza interdependente do corpo com um ambiente, suas relações sociais, suas redes de apoio e suas condições de possibilidade, mas fundamentalmente permite a incorporação das modulações derivadas da vulnerabilidade (DAHBAR, 2018, p. 37) no governo do tráfico sexual; entender a precarização como governamentalidade torna possível problematizar as complexas interações de um instrumento de governo com os modos de subjetivação e as ambivalências entre exploração sexual e empoderamento. As práticas de empoderamento não funcionam de maneira alguma de modo automaticamente emancipatória (LOREY, 2016, p. 28); em outras palavras, devemos considerar que não estamos lidando com a constituição de sujeitos soberanos, mas com práticas específicas de subjetivação, que funcionam de maneira heterogênea e que não buscam a emergência de subjetividades determinadas, mas de reconhecimentos variáveis, híbridos e mutantes (ROSE E VALVERDE, 1998, p. 548).

As modalidades de governo do tráfico sexual, analisadas como uma esfera de governamentalidade, demonstram a natureza ambígua e ambivalente das tecnologias de resgate dispostas para o autogoverno das vítimas. Assim, tentamos destacar a resistência do/as trabalhadore/as sexuais diante do empoderamento 
punitivo e dessas estratégias que são instrumentalizadas para perpetuar o controle do tráfico. Podemos concluir que a precariedade permite a abertura a outros problemas relacionados ao mercado sexual expressos por quem reivindica essa atividade como trabalho, uma vez que incorpora a natureza produtiva do incalculável, do imensurável e do que se recusa a ser enquadrado, retirando-se de um governo baseado na (in)segurança (LOREY, 2016, p.29).

\section{Referências}

ABRAMS, Katrin. 1995. "Sex Wars Redux: Agency and Coercion in Feminist Legal Theory”. Columbia Law Review. Vol. 304. pp.304-376.

AGUSTIN, Laura. 2007. Sex at the Margins: Migrations, Labour markets and the Rescue Industrie. London. Zed Books.

ARADAU, Claudia. 2004. "The Perverse Politics of Four-Letter Words: Risk and Pitty in the Securiti- zation of Human Trafficking”. Millenium Journal of International Studies. Vol.22. No.2. pp.251-277.

ARADAU, Claudia. 2008. Rethinking Trafficking in Women. Politics of Security. London. Palgrave.

BENENTE, Mauro. 2017. "Biopolítica y Tanatopolítica en Michel Foucault y Roberto Esposito”. Reflexión Política, vol. 19, núm. 37, enero-junio, pp. 16-28.

BERLANT, Lauren. 2007. Slow Death (Sovereignty, Obesity, Lateral Agency) Critical Inquiry, Vol. 33, No. 4, (Summer 2007), pp. 754-780.

BERNSTEIN, Elizabeth. 2010. "Militarized humanitarianism meets carceral feminism: the politics of sex, rights, and freedom in contemporary antitrafficking campaigns”. Signs: Journal of Women in Culture and Society. Vol. 36. No.1. pp. 4571.

BERNSTEIN, Elizabeth. “Carceral politics as gender justice?” Theory and Society, Vol. 41, pp. 233-59.

BROWN, K. 2014. 'Questioning the vulnerability zeitgeist: care and control practices with 'vulnerable young people', Social Policy and Society.Vol. 13. No. 3.pp. 371-87.

BROWN, K. 2015.Vulnerability and Young People: Care and Social Control in Policy and Practice. Bristol. Policy Press.

BUMILLER, Kristin. 2008. In an abusive state. Durham. Duke University Press.

BUTLER, Judith. 2006. Deshacer el género. Barcelona: Paidós. 
BUTLER, Judith. Vida precaria. El poder del duelo y la violencia. Buenos Aires: Paidós.

BUTLER, Judith. 2009a. Dar cuenta de sí mismo. Violencia ética y responsabilidad. Buenos Aires: Amorrortu.

BUTLER, Judith. 2010. Marcos de guerra. Las vidas lloradas, México: Paidós.

CHAPKIS, Wendy. 2003. "Trafficking, Migration, and the Law: Protecting Innocents, Punishing Inmi- grants". Gender and Society. Vol. 17. No.6. pp. 923-937.

COLOMBO, Marcelo/MANGANO, Alejandra. 2011. "El consentimiento de la víctima en la trata de personas y un análisis sobre los medios comisivos previstos en la figura penal". Disponible en http:// www.mpf.gov.ar/Accesos/Ufase/consentimiento_victima_trata.pdf (recuperado el 12/3/2014).

DAHBAR, Victoria. 2018. Marcos temporales de la violencia. Hacia una configuración de lo humano-inhumano. Tesis de Doctorado. Facultad de Ciencias Sociales. Universidad de Buenos Aires.

HACKETT, Colleen. 2013. "Transformative Visions: Governing Through Alternative Practices and Therapeutic Interventions at a Women's Reentry Center." Feminist Criminology. Vol. 8. No.3. pp. 221-242.

HALLEY, Janet/KOTISWARAN, Hila S./THOMAS, Chantal. 2006. "From The International To The Local In Feminist Legal Responses To Rape, Prostitution/Sex Work, And Sex Trafficking: Four Studies In Contemporary Governance Feminism”. Harvard Journal of Law and Gender. Vol. 29. pp.336-423.

HANNAH-MOFFAT, Kelly. 2000. "Prisons that Empower: Neoliberal Governance in Canadian Women's Prisons.” British Journal of Criminology. Vol. 40. pp.510531.

HANNAH-MOFFAT, Kelly. 2006. "Pandora's Box: Risk/Need and GenderResponsive Corrections." Criminology and Public Policy. Vol. 5. No. 1. pp. 183-192.

HARCOURT, Bernard. 1999. "The collapse of Harm Principle”. Jorunal of Criminal Law and Crimino- logy, Vol. 90. No. 1. pp. 109-194.

HANNAH-MOFFAT, Kelly. 2008. "Supposons que la discipline et la sécurité n'existent pas - Rereading Foucault's Collège de France Lectures (with Paul Veyne)". Discipline, Security and Beyond. Rethinking Michel Foucault 1978-1979 College de France Lectures. Carceral Notebooks. Vol. 4. pp. 153-173.

HOANG, Kimberley K /SALAZER PARREÑAS, Rachel. 2014. Human Trafficking Reconsidered. Rethinking the Problem, Envisioning new Solutions. New York. The International Debate Education Association.

IGLESIAS SKULJ, Agustina. 2013. La trata de mujeres con fines de explotación sexual. Buenos Aires: Didot. 
IGLESIAS SKULJ, Agustina. 2017. “¿Cómo hacerse la Sueca? Criminalización de la demanda de servicios sexuales: gobernanza de la trata sexual en tiempos de feminismo punitivista. KULA. Antropólogos del Atlántico Sur. Revista de Antropología y Ciencias Sociales. Buenos Aires, Argentina. Número 17. Diciembre. pp.11-24.

KELLY, Liz. 2005. "You can find anything you want": A critical reflection on research on trafficking in persons within and into Europe." International Migration. Vol. 43. Nro.1-2- pp. 235-65.

KEMPADOO, Kamala/DOEZEMA, Jo. 1998. Global Sex Workers: Rights, Resistance, and Redefini- tion. New York. Routledge.

KAPUR, Ratna. 2005. Erotic Justice: Law and the New Politics of Postcolialism. London. The Glass House Press.

KOTISWARAN, Praba. 2014. "Beyond Sexual Humanitarianism: A Postcolonial Approach to Anti-Tra- fficking Law”. Ucirvine Law Review, Vol.4. pp. 353-406.

MAKINNON, Catherine. 1983. Feminism, Marxism, Method And State: Towards A Feminist Jurisprudence, Signs, 8 (2), pp. 635-58.

MAKINNON, Catherine. 1995. Hacia una teoría feminista del Estado. Valencia: Cátedra.

MILLER, Alice. 2004. "Sexuality, Violence Against Women, and Human Rights: Women Make Demands and Ladies Get Protection". Health and Human Rights. 7(2), pp. 16-47.

MUNRO, Vanessa E./ SCOULAR, Jane. 2012. "Abusing Vulnerability? Contemporary Law and Policy Responses to Sex Work in the UK". Feminist Legal Studies. Vol.20, Nro. 3. pp. 189-206.

PISCITELLI, Adriana. 2015 "Riesgos: la capilarización del enfrentamiento a la trata de personas en las tensiones entre planos supranacionales, nacionales y locales". Texto preparado para el IV Congreso Latinoamericano sobre Trata y Tráfico de Personas. Recuperado el 22 de julio de 2018 de https://www.academia.edu/24995943/Riesgos_

la_capilarización_del_enfrentamiento_a_la_trata_de_

personas_en_las_tensiones_entre_planos_supranacionales_nacionales_y_local.

PUAR, Jasbir K. 2011. CODA: THE COST OF GETTING BETTER Suicide, Sensation, Switchpoints. GLQ: A Journal of Lesbian and Gay Studies, Vol. 18(1), pp. 149-158.

RABINOW, Paul y ROSE, Nikolas. 2006. "Biopower Today". BioSocieties, 1, 195217. London School of Economics and Political Science, disponible en http://anthropos-lab.net/wp/publications/2007/o1/rabinow-rose.pdf (visitado 17/6/2018). 
ROSE, Nikolas, O'Malley, Pat y Valverde, Mariana. 2006. "Governmentality". (September) Annual Review of Law and Social Science, Vol. 2, pp. 83-104.

ROSE, Nikolas y VALVERDE, Mariana. 1998. “Governed by Law?”. Social \& Legal Studies. Vol. 7(4). pp. 541-551.

SANDERS, Teela/O `NEILL, Maggie/PITCHER, Jane. 2009.Sex Work, Policy and Politics. London. Sage Publishing.

SAUNDERS, Penelope. 2005. "Traffic Violation: Determining the Meaning of Violence in Sexual Tra- fficking versus Sex Work". Journal of Interpersonal Violence. Vol.20. No.3. pp.343-360.

SAUNDERS, Penelope/SODERLUND, Gretchen. 2003. “Threat or Opportunity? Sexuality, Gender The EEB, and Flow of Trafficking Discourse". Canadian Women Studies. Vol.22. No.22, pp.16-24.

SCOULAR, Jane. 2004. "The Subject of Prostitution: Interpreting the Discursive, Symbolic, and Mate- rial Position of Sex Work in Feminist Theory”. Feminist Theory. Vol.5. No.3. pp. 343-355.

SCOULAR, Jane/O’NEILL, Maggie. 2007. "Regulating Prostitution. Social Inclusion, Responsibiliza- tion and the Politics of Prostitution Reform". British Journal of Criminology. Vol. 47. No. 3. Pp. 764- 778.

SPIVAK, Gayatri Ch. 1988. "Can the Subaltern Speak?" Marxism and the Interpretation of Culture. En: Nelson, C.y Grossberg, L. (Ed) Urbana. University of Illinois Press. pp. 271-313.

TREBISACCE MARCHAND, Catalina. 2020. "Un nacimiento situado para la violencia de género. Indagaciones sobre la militancia feminista porteña de los años 80". Anacronismo e Irrupción, Vol. 10, N 18, (Mayo - Octubre 2020), pp. 118-138.

VALVERDE, Mariana. 2008. "Beyond Discipline and Punish: Foucault's Challenges to criminology. Discipline, Security and Beyond. Rethinking Michel Foucault 1978-1979 College de France Lectures. Carceral Notebooks. Vol. 4. pp. 201223.

VALVERDE, Mariana. 2010. "Questions of Security: A Framework for Research". Theoretical Criminology. Vol. 15. No. 1. pp. 3-22.

VARELA, Cecilia I. 2013. "De la "letra de la ley" a la labor interpretante: la "vulnerabilidad" femenina en los procesos de judicializacion de la ley de trata de personas (2008-2011)". Cadernos Pagu (online). No.41. pp. 265-302. Disponible http://www.scielo.br/pdf/cpa/n41/15.pdf (recuperado el 12/11/2016).

VARELA, Cecilia I. 2015. "La campaña antitrata en la Argentina y la agenda supranacional”. En Daich, D. y Sirimarco, M. (Coords), Género y violencia en el mercado del sexo. Política, policía y Prostitución (pp. 109-149). Buenos Aires: Biblos. 
WEITZER, Roland. 2011. Legalizing Prostitution: From Illicit Vice to Lawful Business. New York. New York University Press.

\section{Informes}

AMMAR/DAICH, Deborah/VARELA, Cecilia I. 2014. Politicas antitrata y vulneración de derechos de las Trabajadoras Sexuales. http://www.ammar.org.ar/IMG/pdf/informe-ammar.pdf

AMMAR/RedTraSex. DAICH, Deborah/VARELA, Cecilia 2016. Trabajo Sexual Y Violencia Institucio- nal: Vulneración De Derechos Y Abuso De Poder Hacia Mujeres Trabajadoras Sexuales. http://www. redtrasex.org/IMG/pdf/informe_nacional_argentina.pdf

AMNESTY INTERNATIONAL. 2016. Lo que hago no es un delito”. El coste humano de penalizar el trabajo sexual en la Ciudad de Buenos Aires, Argentina. https://www.amnesty.org/es/documents/ amr13/4042/2016/es/

Recebido em: 30/06/2020. Aprovado em: 04/08/2020. Publicado em: 15/08/2020. 